\title{
Microstructure and Tribological Behaviour of CrCuFeNiTi High Entropy Alloys
}

\author{
Kehinde Sobiyi ${ }^{1,3, a}$, Michael Bodunrin ${ }^{2}$, Esther Akinlabi ${ }^{3}$ and Babatunde Obadele ${ }^{4}$ \\ ${ }^{1}$ School of Chemical and Metallurgical Engineering, University of the Witwatersrand, South Africa \\ ${ }^{2}$ Department of Metallurgical and Materials Engineering, Federal University of Technology, Akure, PMB 704, Nigeria \\ ${ }^{3}$ Department of Mechanical Engineering Science, University of Johannesburg, South Africa \\ ${ }^{4}$ Department of Chemical Engineering, University of Johannesburg, South Africa
}

\begin{abstract}
The microstructure, hardness and wear performance of CrCuFeTiNi high entropy alloy were evaluated. The alloy was produced by mixing constituent elements, consolidated and melted using vacuum arc furnace. The X-ray diffraction analysis confirmed that the alloy is composed of FCC and BCC simple phases. The microstructure contains three regions that were rich in $\mathrm{Cu}, \mathrm{Cr}$ and $\mathrm{Fe}$ which resulted from segregation of constituent elements. The Vickers micro hardness of the alloy was determined as $\mathrm{HV}_{0.5}=510 \pm 7 \mathrm{MPa}$. The wear performance of the alloy was also studied using WC balls under two load conditions. The volume loss was evaluated, accompanied by analysis of the wear tracks and debris using SEM images and EDS. The main wear mechanisms were ploughing, adhesion and oxidation-dominated wear.
\end{abstract}

\section{Introduction}

New design concept in alloy development was established independently by Yeh [1] and Cantor [2] about eleven years ago. The concept involved the production of solid solution metallic systems containing a minimum of five elements in equiatomic or equimolar ratios. These metallic systems are referred to as high entropy alloys (HEAs). Unlike in traditional metallic systems, where one element serves as the matrix and other alloying elements are carefully added in specified proportions, to avoid the formation of unwanted phases, HEAs are known to have simple structures such as face centered cubic (FCC), body centered cubic (BCC) or a mixture of both (FCC+BCC) structures [3]. This unique attribute of HEAs has been ascribed to high entropy of mixing which often suppresses the formation of metastable and complex phases [4].

In previous studies, it was reported that HEAs are becoming increasingly attractive for use in several engineering fields due to superior mechanical [5], corrosion [6] and tribological properties [7] over the conventional alloys. In addition, the ability of HEAs to retain some of its unique properties at high temperatures has made the alloys a potential substitute for nickel based super alloys in high temperature environments as well as for making machine tools where creep and wear resistant materials are desirable.

In this research, an attempt has been made to develop new CrCuFeTiNi high entropy alloy. The microstructural features and wear performance were examined.

\footnotetext{
${ }^{\mathrm{a}}$ Corresponding author:kk_sob@yahoo.com
} 


\section{Experimental Procedure}

Elemental powders of $\mathrm{Cr}, \mathrm{Cu}, \mathrm{Fe}, \mathrm{Ni}$ and $\mathrm{Ti}$ (purity $99.5 \mathrm{wt} \%$ ) were mixed in a planetary ball mill for $6 \mathrm{hrs}$ at $250 \mathrm{rpm}$. The mixed powder compositions was compacted and arc-melted in a high-purity argon atmosphere. The melting process was repeated three times to improve the homogeneity of the alloys.

The microstructure of the as-cast samples were observed using a scanning electron microscopy (SEM, TESCAN), equipped with Oxford instrument energy dispersive X-ray spectrometer (EDS). The alloys phase constitutions were analysed with an X-ray diffractometer (X-bunker) with $\mathrm{Cu} \mathrm{K} \alpha$ radiation operated at $40 \mathrm{kV}, 30 \mathrm{~mA}$. Vickers testing machine (EMCOTEST ${ }^{\circledR}$ ) was used to determine the microhardness of the sectioned and polished samples under a test load of $500 \mathrm{~g} / \mathrm{f}$ and dwell time of 10 seconds. Fifteen indentations were applied per sample and the average values were recorded.

Dry sliding wear test was performed on the samples using the ball on disk tribometer (CETR UMT-2, now Bruker Nano Inc. Campbell, CA). Tungsten carbide ball of diameter $9.5 \mathrm{~mm}$ was applied at normal loads of $25 \mathrm{~N}$ and $35 \mathrm{~N}$ for a period of 1000 seconds at a frequency of $5 \mathrm{~Hz}$. The wear volume loss was plotted. The sample worn surfaces were analysed under the SEM. The schematic diagram of the experimental procedure is shown in Figure 1.

Wear volume loss of material on the substrate is calculated from Equation 1.

$V_{\text {total }}=V_{A}+V_{B}=L\left\{r^{2} \sin ^{-1}\left(\frac{W}{2 r}\right)-\frac{W}{2}\left(r^{2}-\frac{W^{2}}{4}\right)^{1 / 2}\right\}+\frac{\pi}{3}\left\{2 r^{3}-2 r^{2}\left(r^{2}-\frac{W^{2}}{4}\right)^{1 / 2}-\frac{W^{2}}{4}\left(r^{2}-\frac{W^{2}}{4}\right)^{1 / 2}\right\}$

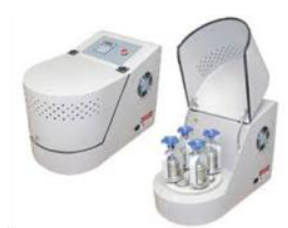

1. Powder Mixing

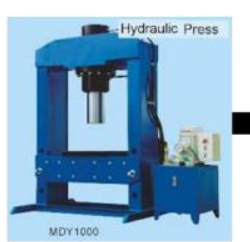

2. Powder compaction
3. Arc melting
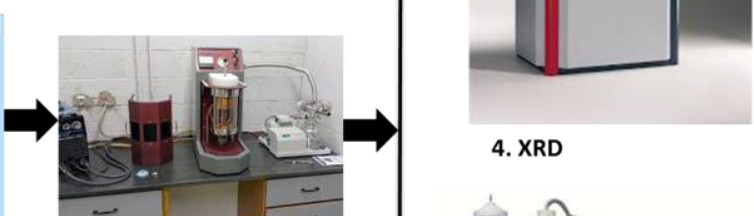

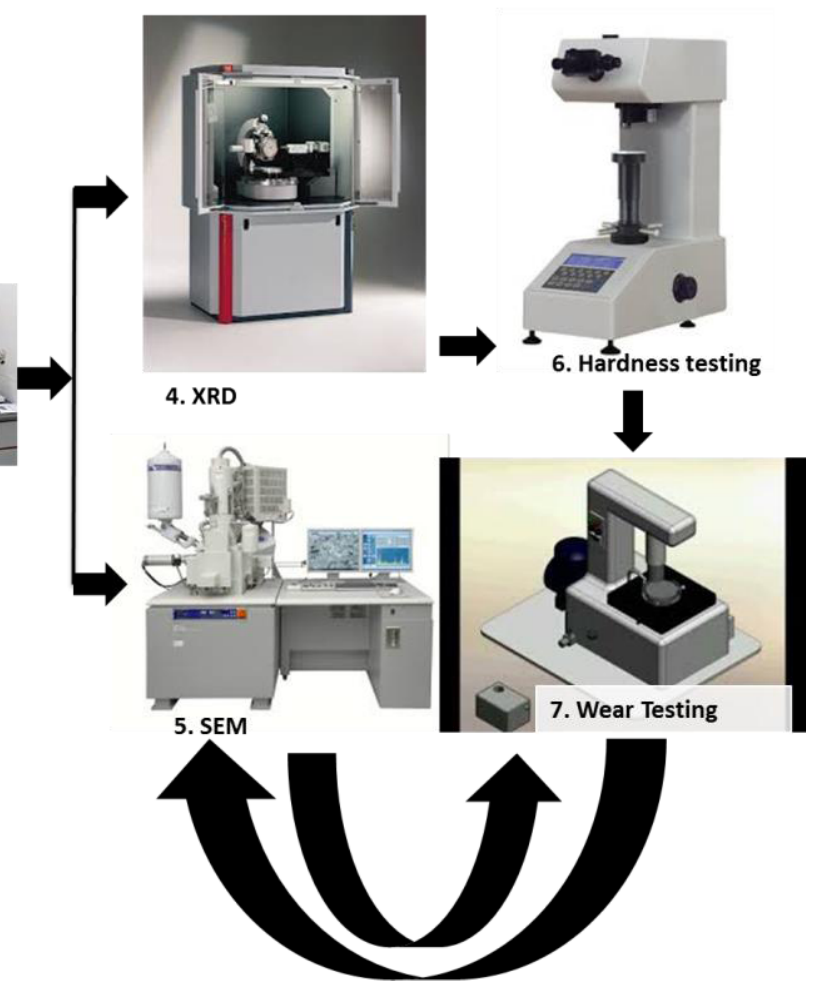

Figure 1. Schematic diagram of the experiments

\section{Results and discussions}

\subsection{Phase analysis and microstructure of the alloys}


The XRD pattern of the CrCuFeNiTi high entropy alloy is shown in Figure 2. It can be observed that the $\mathrm{CrCuFeNiTi}$ alloy composed mainly of simple phases of face centered cubic (FCC), and body centered cubic (BCC). The presence of $\mathrm{Ti}$ in the alloy helps to strengthen the alloy due to its large negative enthalpy of mixing with the other elements in the composition. The phase formation is determined by the competition between the enthalpy and entropy [7].

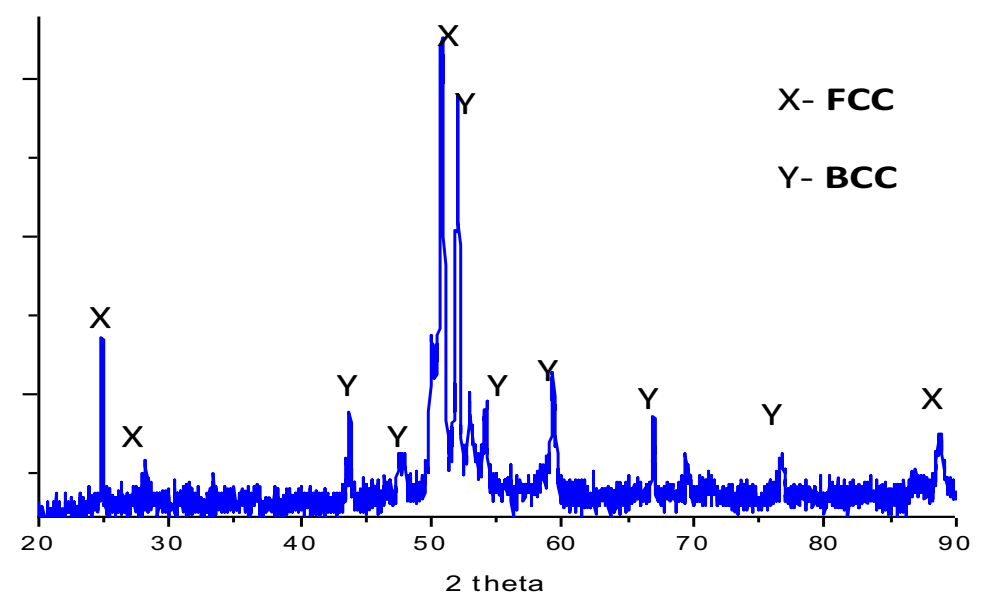

Figure 2. XRD pattern of the CrCuFeNiTi high entropy alloys

The SEM/BSE image of the CrCuFeNiTi alloy is presented in Figure 3. It is observed that the microstructure contains three majors regions (region I-light, region II greyish dark and region III-grey) with an agglomeration of black dot-like structure dispersed mostly within the dark-greyish and grey regions. EDS spectra for each region is shown in Fig. 2/ Table 1, region I which is the light phase is rich in $\mathrm{Cu}, \mathrm{Cr}$ is/are dominant in region II (greyish dark) while region III (grey) is predominantly Fe. The high amount of different elements contained in different regions confirmed segregation of elements during the production of the alloy. $\mathrm{Cu}$ segregation in $\mathrm{Al}_{x} \mathrm{CoCrCuFeNi}$ HEA has been reported by [8].

The microhardness of the alloy is $510 \pm 7 \mathrm{HV}_{0.5}$. The hardness is as a result of the presence of titanium in the alloy, thus enhancing expansion lattice [9].

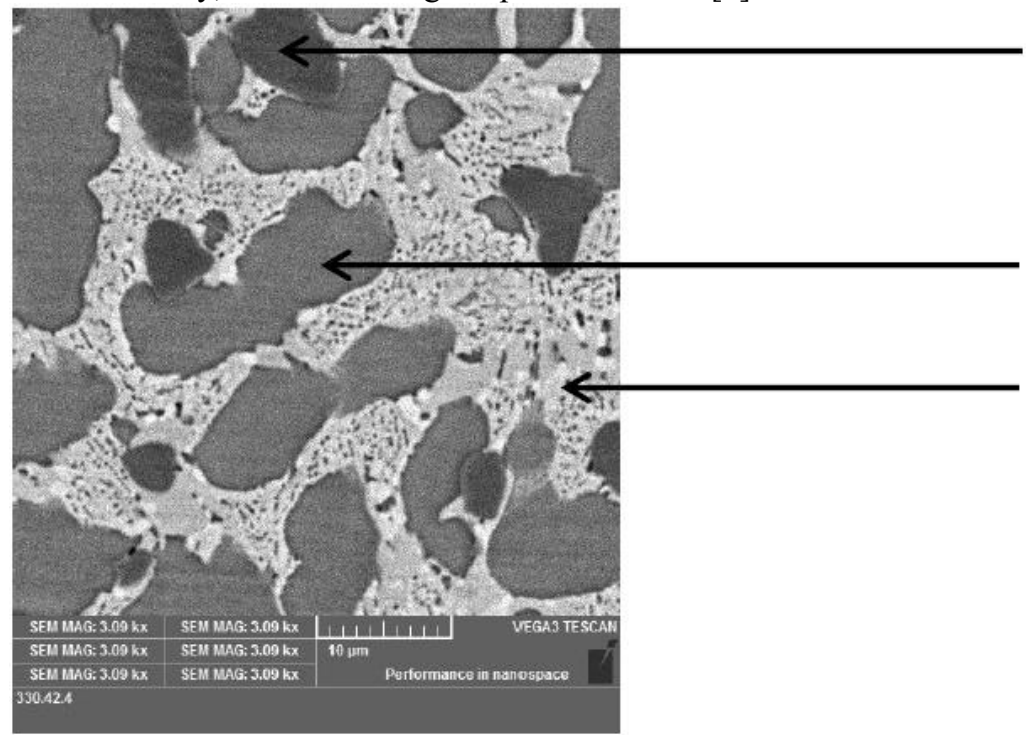

Region I

Region II

Region III

Figure 3. SEM micrograph of the CrCuFeNiTi high entropy alloy 


\subsection{Wear resistance behaviour}

To understand the wear mechanism on the $\mathrm{CuCrFeNiTi}$ alloy against $\mathrm{WC}$ balls during reciprocating sliding condition, the wear tracks on the surfaces of the alloy under two different loads of $25 \mathrm{~N}$ and 35 $\mathrm{N}$ were observed by SEM as shown in Figure 3. Wear tracks comprised abraded regions with continuous microgrooves parallel to the direction of sliding. The presence of plastic deformation in the sliding contact area is responsible for the surface morphology [10]. There were many accumulated fine and irregular wear debris particles, delaminated scars on the worn tracks and micropatches within the worn zone. From the EDS point analysis of the debris, elemental oxygen, iron and titanium were detected which showed that the alloy experienced considerable oxidation (presence of oxygen) as evidenced by the formation of materials accumulation regions as shown in Fig. 4d. The main wear mechanism is in the form of oxidation-dominated wear as evident by the presence of oxygen in the debris and also adhesion wear with ploughing.

The wear volume loss plot against the applied load is shown in Figure 5. There was a marginal increase in the material volume loss from about $0.35 \mathrm{~mm}^{3}$ to $0.36 \mathrm{~mm}^{3}$ as the applied load is increased from $25 \mathrm{~N}$ to $35 \mathrm{~N}$.
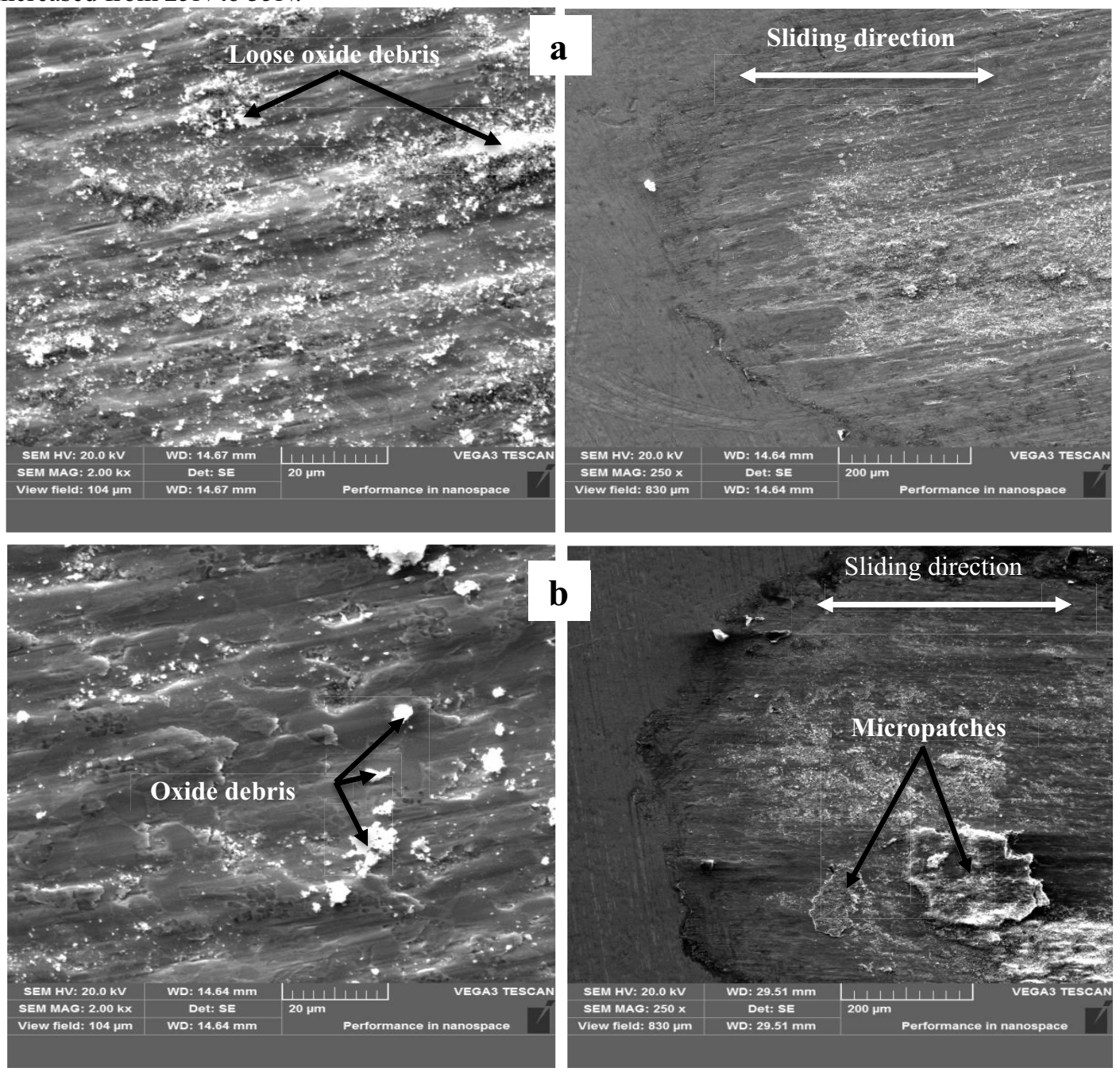

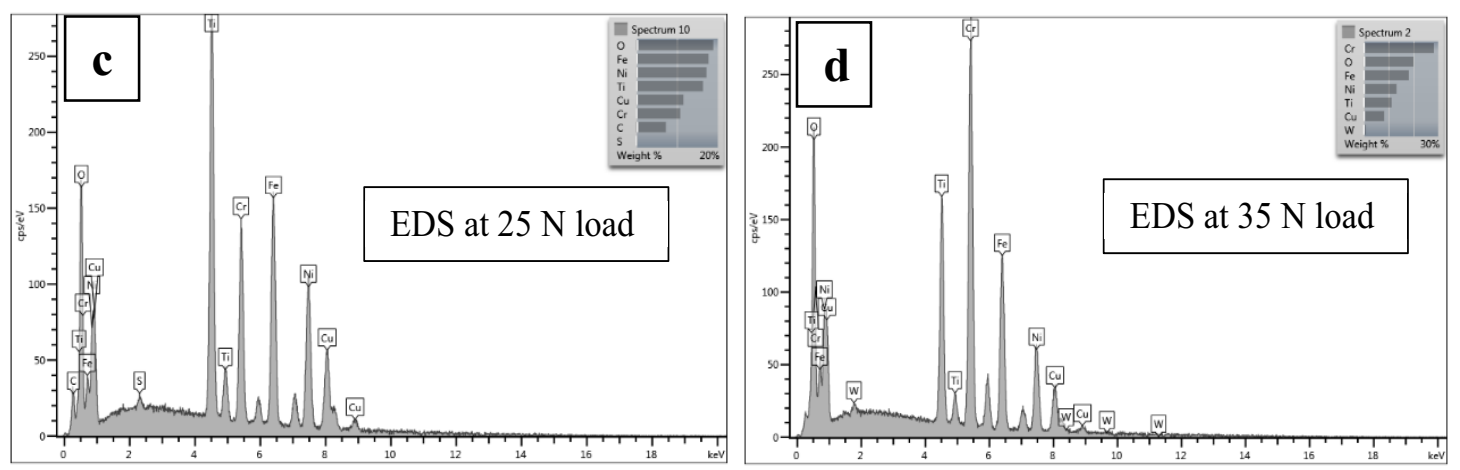

Figure 4. SEM images of the worn surface and the corresponding EDS spectra of $\mathrm{CuCrFeNiTi}$ alloy under applied load of $(\mathrm{a}, \mathrm{c}) 25 \mathrm{~N}$ and $(\mathrm{b}, \mathrm{d}) 35 \mathrm{~N}$.

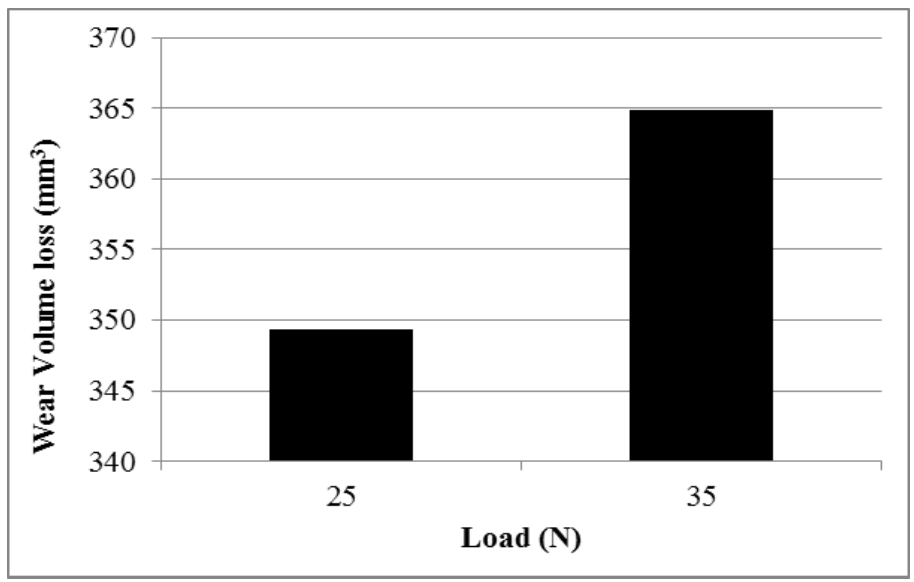

Figure 5. Wear volume loss of the alloy under different loads

\section{Conclusions}

The study investigated the microstructure and the wear performance of CrCuFeTiNi high entropy alloy produced by arc melting. The following results were obtained:

- The alloy consisted of simple BCC and FCC phases. It is also observed that the microstructure contains three majors regions; $\mathrm{Fe}$ rich, $\mathrm{Cr}$ rich and $\mathrm{Cu}$ rich regions.

- Vickers microhardness of the alloy is determined as $510 \pm 7 \mathrm{HV}_{0.5}$. The hardness is as a result of the presence of titanium in the alloy.

- Wear tracks comprised abraded regions with continuous microgrooves parallel to the direction of sliding. The main wear mechanism is in the form of oxidation-dominated wear as evident by the presence of oxygen in the debris and also adhesion wear with ploughing.

\section{References}

1. J.W. Yeh, S.K. Chen, S.J. Lin, J.Y. Gan, T.S. Chin, T.T. Shun, C.H. Tsau, S.Y. Chang, Adv. Eng. Mater., 6, 299-303 (2004)

2. B. Cantor, I. Chang, P. Knight, A. Vincent, Mater. Sci. Eng. A, 375-377 (2004), pp. 213-218

3. H. Zhang, Y. Pan, Y. He, H. Jiao, Appl. Surf. Sci, 257, 2259-2263 (2011)

4. T.T. Zuo, X. Yang, P.K. Liaw, Y. Zhang, Intermetallics, 67, 171-176 (2015)

5. F.J. Wang, Y. Zhang, G.L. Chen, H.A. Davies, Int. J. Mod. Phys. B, 2, 1254-12593 (2009) 
6. X.W. Qiu, Y.P. Zhang, Mater. Sci. Eng. Power Metall., 17, 377-382 (2012)

7. J. M. Wu, S. J Lin, J W Yeh, S. Chen, Y haung, H Chen, Wear, 261, 513-519 (2006)

8. M.Tsai and J. Yeh, Mater. Res. Lett., 2, 107-123 (2014)

9. W. Wang, W. Wang b , J. Yeh, J. Alloys Comp., 589, 143-152 (2014)

10. S. Ge, S. Wang, N. Gitis, M. Vinogradov and J. Xiao, Wear, 264, $571-578$ (2008) 